\title{
Herramientas para una endocultura feminista
}

\author{
Páez Cruz, Iris \\ Universidad de La Laguna (ULL), San Cristóbal de La Laguna, España. \\ iris.paez.2a@gmail.com \\ Perera Méndez, Pedro \\ Universidad de La Laguna (ULL), San Cristóbal de La Laguna, España. \\ ppereram@ull.edu.es
}

\section{Resumen}

Vivimos en una sociedad patriarcal y androcéntrica que se mantiene y se reproduce entre generación y generación hasta nuestros días. De hecho, en el ADN de esta sociedad la falta de conciencia sobre la igualdad, incluyendo el problema de género, se conforma en un rasgo cultural, económico, social y político que se trasmite intergeneracionalmente en pos de una reproducción foucaultiana de relaciones consideradas determinantes. Por medio de la endoculturación, a través de valores y normas patriarcales, se ha generalizado la creencia de que existen aspectos diferenciados en relación al género, constituyendo la creencia hegemónica de que los aspectos «masculinos» son los universales y dominantes. Por lo que, a todas las personas de la sociedad nos van cargando en la espalda una gran mochila de ideas, valores, mandatos y órdenes de lo que esperan de nosotras. Es una mochila que, a no ser que se cuestione desde una multiplicidad de perspectivas, llevaremos toda nuestra vida. De esta manera nos preguntamos, ¿necesita la igualdad desechar la endocultura actual para así poder desprendernos de estas mochilas de ideas y valores?. La cuestión que nos corresponde es analizar si ha habido modificaciones, sea en el sentido que sea, en positivo o en negativo acerca de la visión y el tratamiento de la desigualdad de género como elemento integrado en los procesos endoculturales de generaciones anteriores. Al analizar estas modificaciones, hay que detenerse a re-plantear qué se puede proponer para trabajar la endoculturación patriarcal inculcada y cómo acelerar el cambio. Teniendo en cuenta la diversidad de herramientas e instrumentos que tenemos a nuestra disponibilidad, el proceso de empoderamiento o cambio puede darse por medio de diferentes vías; medios de comunicación, redes sociales, entornos informales, etc. Pero siempre bajo la supervisión de una herramienta clave; la educación feminista hacia una sociedad igualitaria.

\section{Abstract}

The patriarchal society we live in is constantly displayed and reproduced. Indeed, this society rooted in lack of equality awareness, including the gender issue, is characterized by social, economic, political, and cultural traits that are transmitted between generations. Through generalizing the idea that there exist different attributes related to each gender, there has been created the concept of «masculine» traits as universally dominant. However, does this necessarily mean that the process for equality should disregard today's conceptions as a whole? There is the need to stop and analyze whether there have been any changes, either positive or negative, in regards to views and conceptions included in the "endoculture» process of previous generations. Research should focus on how to accelerate change taking into account the multiple tools to use. This process of empowerment, rather than change, can be accomplished through various ways. The media, social networks, informal meetings, are all useful; ways, but they must always be managed under the most relevant tool: education with feminist ideals.

Palabras clave: Endocultura, Igualdad, Juventud, Gender, Educación.

Keywords: Endoculture, Equality, Youth, Gender, Education. 


\section{INTRODUCCIÓN. AGENCIAS DIFERENCIADORAS QUE DICTAN LEYES NATURALES.}

Es indiscutible el poder que el lenguaje y la comunicación posee para cualquier proceso de endoculturación y sin quererlo, tendemos a reproducir esquemas socioculturales y legitimar el sistema dominante. Generación tras generación reproducimos un modelo patriarcal que brilla por el dominio de los hombres y la subyugación de las mujeres en diferentes ámbitos, diferenciando los comportamientos de ambos bajo roles sociales impuestos en este modelo.

Este trabajo pretende captar la diferencia existente entre las generaciones anteriores y la actual acerca de creencias y mitos que apuntalan de forma indeleble los roles otorgados a cada cual. El andamiaje se presenta como verdades de titanio que aguantan impresionantes fuerzas sin padecer siquiera un mínimo deterioro. Las intenciones pasan por seguir el método Foucaultiano. Un marco de interpretación que busca perturbar la estabilidad de explicaciones que se consideran inamovibles, intentando fragmentar aquellas interpretaciones sociales que parecen sólidas y unificadas. Trataremos por tanto, de buscar las posibles grietas o fisuras del sistema, sobretodo en la repartición de roles de género, centrándonos en el apego entre madre e hijo y en el mito del instinto materno, así como las diferentes responsabilidades e imposiciones sociales que este conlleva. Y no porque no se crea que la relación entre una madre y su hijo no fuera importante sino por lo que ello conlleva en relación a sus funciones, sus tareas y sus responsabilidades que desplazan figuras posibles y toda una serie de nuevas relaciones como mínimo en el espacio privado de la familia.

Por tanto, el objetivo principal de esta comunicación se centra en poner en jaque y en su caso, desmontar el discurso creado tras años de repetición e imitación cultural del modelo hegemónico actual, en el que el peso de los cuidados y maternidad reside únicamente en el papel de la mujer, dejando a un lado de forma considerable el rol masculino en todo este proceso. No obstante, no se trata de llamar a perder un espacio, sino un intento de recolocar a los sujetos en el espacio familiar bajo una visión real de igualdad, basada en las oportunas necesidades pero mediadas por informaciones contrastables más allá de la tradición. Negociando bajo una visión diferenciada pero siempre equitativa, de los roles a ejecutar por los hombres y por las mujeres, dejando en evidencia que los sentimientos de índole machistas no sólo se encuentran en los hombres, sino en ambos géneros y que son trasmitidos de forma constante por las figuras y agencias educativas.

Es por ello, por lo que habrá que partir de un proceso en el que hay que desaprender y desmontar para así poder educar. En definitiva, no se trata de quitar el privilegio de la madre de estar con el niño, se trata de recolocar ambas figuras, proporcionando un espacio a la figura paterna en la crianza de los hijos, tanto en su responsabilidad para con la criatura como en su disfrute, a la par de ampliando las posibilidades sociales, políticas, económicas y personales que dicha participación generan a la madre.

\section{APUNTALANDO LO CONSTRUIDO. EL INSTINTO MATERNAL.}

Hacia el final del siglo diecinueve, la teoría de Charles Darwin donde afirma que tanto los animales como los humanos descienden de la misma especie, logró influenciar muchas teorías sociales de la época. Darwin sostenía que los seres humanos y los animales actúan a través de instintos, es decir, actuaban a través de características fijas heredadas y compartidas por todos los miembros de una especie. En ese sentido, la mayoría de los estudios de la época intentaban identificar los instintos humanos para así describir la conducta de las personas. No se va a entrar en lo esquizoide del momento en el que por un lado se encuentra un aparente sustrato igualitario del ser humano y por otro se avecinaba las mayores atrocidades en nombre de la diferenciación de grupos humanos. De dichas intenciones para con los instintos animales en referencia al ser humano nacería el supuesto instinto maternal de las mujeres. No obstante, a comienzos del siglo veinte el concepto de instinto comenzó a perder actualidad y la noción de que la conducta humana está determinada por el aprendizaje o factores ambientales comenzó a ganar, de nuevo, un mayor terreno.

\footnotetext{
${ }^{1}$ Aunque no se debe dejar de incidir en que todo espacio interrelacional es un espacio político que interfiere con lo público de formas no directas en muchos casos pero con incidencias importantes. Esta afirmación se realiza desde la perspectiva ecológica-sistémica de las Ciencias Sociales.
} 
Pese a ello, la sociedad está muy apegada a las costumbres trasmitidas - impuestas - mediante la religión, la cultura hegemónica y a la trasferencia de costumbres y valores. En este sentido, el mito del instinto materno conlleva a su vez problemáticas vigentes tales como: el aborto, la elección de la no maternidad, maternidades diferentes y hasta subversivas... pero, frente a estas críticas nos preguntamos, ¿de dónde viene la creencia popular de que todas las mujeres tienen un instinto innato y universal de maternidad?

La familia es una estructura social básica. Se conforma como núcleo de socialización y no faltan estudios de autores de un y otro signo ideológico, moral, social, económico, etc. donde no se reconozca la gran importancia de la familia dentro de cualquier sociedad humana. Como fundamento común se puede decir que se afirma en un porcentaje muy elevado de estudios que es en la familia donde cotidianamente se van proporcionando las bases del desarrollo infantil, influyendo en la construcción de la identidad de cada uno de los miembros de la misma como prsona pero siemrpe desde su pertenencia a este grupo básico.

Peter Berger, en su teorías de construcción social ya afirmaba que el ser humano se forma en interacción con su ambiente cultural y el orden cultural y social. La sociedad es un producto humano y esta a su vez es una realidad objetiva, en el que el ser humano es un producto social. Por medio del lenguaje, sedimenta y objetiva las experiencias compartidas y las hace accesibles a todos los que pertenecen a la comunidad lingüística, favoreciendo los procesos de endocultración. Son los adultos quienes plantean los conocimientos, las actitudes y los valores de los nuevos y nuevas miembros del grupo familiar.

A través de este proceso de endoculturación o condicionamiento cultural, es como logramos crear nuestros esquemas de pensamiento y por tanto, nuestra manera de ver el mundo que nos rodea. Con la adquisición del lenguaje construimos nuestro propio pensamiento. Sin embargo, como naturalizamos este proceso, muchas veces no somos conscientes de la intencionalidad del lenguaje, de su falta de neutralidad y de su carácter vertical y directivo a través del hecho endoculturador.

Es necesario hacer referencia al uso del lenguaje, el cual desencadena dos situaciones; por un lado la obligación de la madre hacia los hijos por medio de un vínculo sagrado que va más allá de lo social; y por otro lado provoca la desafección del padre dada esta exclusión. Este pensamiento parte de la idea de "comunicación» existente entre la madre e hijo durante el embarazo, una "comunicación» que comienza desde el intercambio de sangre, provocando todo ello, la exclusión de la figura paterna desde los primeros momentos, no sólo una exclusión biológica, sino pública y social. La figura excluida, no podemos dejar de decir que muchos parecen encantados con esta situación, se otorga otros tipos de roles respecto a quien está por venir.

Sin embargo, cualquier proceso comunicativo necesita de un receptor, emisor y mensaje, y dada esta falta de coherencia entre el significado del término y su utilización cotidiana, ¿no se trataría más bien de un intercambio entre madre e hijo, y simplemente por medio de esta endoculturación estamos idealizando la maternidad?

Elisabeth Badinter, filósofa y feminista francesa, ya indagó sobre las bases del instinto maternal. En su libro, "Historia del amor maternal. Siglos XI-XX2», mediante un análisis crítico de los cambios que la mujer se ve obligada a llevar entre los siglos XVII y XX, ofrece numerosos ejemplos que evidencian cómo antes del siglo XVIII, el «amor materno» no existía como institución. No obstante, a partir de 1760 , el destino de las mujeres cambiaría notablemente debido a la visión economista que se le incorporó a la maternidad. Es decir, las autoridades se percataron de la importancia que tenía en el ámbito económico la densidad poblacional y comprendieron que el ser humano era una herramienta valiosa para el Estado, no sólo por las riquezas producidas, sino también porque garantizaba su poder militar. En ese momento comenzó a considerarse que toda pérdida humana era una carencia para el Estado, teniendo en cuenta que la estructura que seguía el Estado ya venía marcada por su condición androcentrista. Aunque durante siglos se ha hecho un esfuerzo sistemático por hacernos creer que el orden impuesto en nuestra sociedad por el patriarcado es el «natural» y único aceptable, Badinter señala que existen realidades distintas a las nuestras, en las que el mito del «amor materno» no existe, y delata la manera en que se alude a las mismas desde el machismo eurocentrado, señalando que no se trata de una actitud universal. Planteando qué clase de instinto es éste que se manifiesta en unas

\footnotetext{
${ }^{2}$ Badinter, Elisabeth (1991). ¿Existe el instinto maternal?. Historia del amor maternal. Siglos XVII al XX en https://es.scribd.com/document/110721050/Badinter-Existe-el-instinto-maternal-Historia-del-amor-maternal-Siglos-XVII-al-XX.
} 
mujeres sí y en otras no. Sin ir más lejos, el instinto de alimentación es un proceso que todos los seres vivos poseemos por mera supervivencia, no podemos elegir si tenemos hambre o no, pues los instintos no son opcionales. Por tanto se podría decir que el instinto materno es una influencia apoyada por la religión y la cultura, ya que si la mujer está amarrada a la maternidad, el resultado sirve como una forma de dominio del sistema patriarcal. El feminismo ha generado históricamente distintas propuestas para analizar la maternidad y sus implicaciones. De Beauvoir es una pionera en ello, pues en 1949 cuestionó la idea de la feminidad y negó el carácter natural del instinto maternal, negando que existiese un destino biológico femenino. Objetó la identificación de lo femenino con lo materno, ya que la maternidad resultaba una atadura en tanto idealización de un rol social, ejercido como única posibilidad de realización femenina. Se reconfigura como imperativo cultural e incluso moral: el de ser y ejercer como madre. Durante su obra «El otro sexo», dedica unos capítulos para recorrer todas las etapas de la vida de una mujer afirmando que desde la infancia hasta la edad adulta se educa a la mujer en la subordinación, transmitiéndolo a sus hijas y nietas.

El ser humano al nacer necesita de un otro que lo cuide, que lo proteja, pues resulta evidente que un bebé no puede crecer ni desarrollarse por sus propios medios dada su dependencia. Pero no necesariamente debe ser una responsabilidad exclusiva de la mujer. A pesar de ello, las madres son designadas socialmente para cumplir estas funciones de cuidado, estableciéndose en ellas una dosis importante de culpa y carga emocional: son responsables de un individuo pequeño y vulnerable.

La maternidad, tal como la concebimos en el siglo XXI, mantiene el orden social- heterosexual y legitima la «esencia» femenina que completa a las mujeres. Es una construcción cultural multideterminada que se organiza a través de normas. Éstas se establecen de acuerdo a las necesidades de los grupos sociales y se enmarcan en una época definida de su historia.

El ideal de la crianza perfecta y de maternidad que venden continuamente en medios de comunicación, redes sociales, discursos de las industrias médicas y la sociedad en su conjunto, hacen que la maternidad posea un mayor peso para las mujeres. En estos discursos se les transmite determinadas prescripciones, incluso antes de que nazcan sus hijos. Se le suscita a las madres estar atentas y al servicio de las necesidades de su bebé durante las veinticuatro horas del día. Pero en estos discursos, ¿dónde queda el papel del hombre en la crianza del hijo?, ¿existe por el contrario un «instinto» paterno que no está siendo valorado socialmente? Nadie habla de «instinto paternal», sino de padres que "ayudan», que "se ocupan» pero siempre desde un segundo plano, sin ser los protagonistas de la crianza. Y cuando lo son, se les mira como rarezas o héroes. Personas capaces de hacer maravillas para las que no están preparados.

Juliet Mitchell planteó que las mujeres podían liberarse de los responsabilidad total de la maternidad si los Estados asumían las funciones de cuidado y crianza de los hijos. Algo con lo que Platón ya fantaseaba en La República, donde imaginaba una sociedad en la cual la maternidad pasaría a ser una tarea comunitaria.

Son numerosas las consecuencias que florecen debido a esta presión ejercida a las mujeres desde que son niñas con la maternidad, mediante juguetes sexistas, comentarios continuos sobre maternidad, medios de comunicación, etc. La socióloga Orna Donath, plantea en su libro «Madres Arrepentidas» los testimonios de veintitrés mujeres que, si pudieran, habrían elegido otro camino diferente. Da visibilidad a una realidad que existe y siempre ha existido, una realidad que ha sido oculta bajo los intereses del sistema capitalista y patriarcal, señalando y juzgando a aquellas mujeres que no responden ante el modelo maternal impuesto.

Junto a ello, en el documental «[m]otherhood», la educadora social Irati Fernandez señala «Hemos elevado la maternidad como una experiencia súper romántica y perfecta, que nos va a proporcionar felicidad y satisfacción constante. Pero hay una cara oculta, que históricamente se nos ha escondido. Es un tabú3»».

A lo que se refiere a la «idealización de la maternidad», un concepto que se ha creado sobre una idea que no es real, sino una construcción social y cultural.

Por lo tanto al no tratarse de un instinto maternal, innato y universal, ¿se trataría más bien de una tendencia a la maternidad? Y esta tendencia generalizada, ¿se ha visto condicionada a los intereses

${ }^{3}$ Documental [m]otherhood. (2015) SUICAFilms. 
de un sistema patriarcal y capitalista con fines muy concretos? ¿Cómo interviene el mito del instinto maternal en el control social de las mujeres?

Lo que nos ha hecho comenzar esta comunicación ha sido el pensar que la cosa no tiene que ir en la lógica feminista de igualdad entre quienes deciden tener descendencia sino que se sigue apuntalando de forma fragante las ideas descritas anteriormente.

\section{RENOVANDO EL DISCURSO. LA CIENCIA AL RESCATE. EL APEGO.}

Una de las grandes agencias de la moderna deidad de la maternidad es el «apego». El término de apego -etimológicamente "unir con pez»- consiste en la vinculación existente y construida entre dos personas producto de la interacción social y afectiva entre ambas. Ello no quiere decir que no existan responsabilidades y satisfacciones sino que dicho vínculo se genera por razones diversas y complejas. El ejemplo típico, tópico... sería la relación madre e hija o hijo. Decir que para el sostenimiento de la importancia de la relación mencionada como ejemplar, casi siempre se utilizan los contraejemplos donde aunque una de las partes no cumpla con su «contrato vincular», la otra parte sigue estando apegada. Madres que no responden a necesidades de sus descendientes y aún éstos reclaman su vinculación... hijas e hijos que no respetan a sus progenitoras y aún éstas reclaman su vinculación. Es por ello, por ejemplos manidos que se acercan más a dilemas ontológicos que a resultados de investigaciones concretas, el término y el propio concepto ha sido foco de grandes y diferentes investigaciones a lo largo del tiempo.

Ya en la primera mitad del siglo XX se trataba de analizar los comportamientos y conductas humanas por medio de diferentes paradigmas nacidos durante la época. Los principales representantes de los paradigmas imperantes en psicología fueron Sigmound Freud, con su teoría del psicoanálisis y B.F. Skinner, y su defensa del conductismo. Estos sostenían que el afecto entre madres e hijos venía de la alimentación, o más concretamente de la lactancia. Plantearon que las conductas afectivas de madres y bebés venían gracias a la simple necesidad de ser alimentados, por lo que el papel principal de las madres consistía en proveer de alimento. No obstante, esta teoría se vio amenaza gracias a los experimentos planteados por John Bowly y Harry Harlow.

John Bowly, a través de diferentes investigaciones realizadas tras la Segunda Guerra Mundial, planteó que los vínculos emocionales que surgen entre madre y descendiente, no vienen dados por la alimentación que esta predispone, sino por otros factores como el cariño familiar y la relación familiar que tenga este durante sus primeros años de vida. John Bowly define la teoria del apego como:

«(...) un modo de concebir la propensión que muestran los seres humanos a establecer sólidos vínculos afectivos con otras personas determinadas y explicar las múltiples formas de trastorno emocional y de alteraciones de personalidad, incluyendo aquí la ansiedad, la ira, la depresión y el apartamiento emocional, que ocasionan la separación involuntaria y la pérdida de seres queridos.»

Por otro lado, Harry Harlow se dedicó en Estados Unidos durante los años setenta a estudiar dentro del laboratorio la teoría del apego y de la privación maternal de Bowlby, empleando para sus experimentos ejemplares de una raza de monos, los Rhesus. En sus experimentos, básicamente separaba a algunas crías de sus madres y observaba de qué manera expresaban su privación maternal. Bowly daba a los monos dos alternativas, por un lado elegir entre una estructura de alambre con un biberón lleno incorporado y por otro lado una figura similar a un macaco adulto, recubierto con felpa suave, pero sin biberón. Los resultados dejaron en evidencia que el vínculo madre-hijo iba más allá de la búsqueda de satisfacer las necesidades biológicas básicas (alimento en este caso ) y existía una necesidad de contacto social para un correcto desarrollo psicológico.

No obstante, es necesario tener en cuenta que estas teorías del apego nacen en los sesenta, época en la que las mujeres tenían la total responsabilidad de crianza siendo la figura principal del apego, dejando a un lado el papel del hombre en este aspecto, y limitando las responsabilidades de roles de género impuestos por la sociedad patriarcal. Junto a ello, ¿es suficiente este experimento con monos para aceptar la teoría del apego?, ¿es extrapolable a todas las especies existentes, incluyendo a los humanos? 
Estas cuestiones no proponen el estudio o de primates encerrados en jaulas y expuestos a privaciones que consideramos básicas sino el factor comunicativo de dichos roles y necesidades referidos a una sola figura de los progenitores. En los actuales tiempos, en los que el espacio del cuidado de los descendientes - casi debiéramos referirnos en singular a dicho término- se encuentra en un momento de ampliación, lento pero parece ser continuo e incorporando a la figura masculina. La implicación se va haciendo visible y es un triunfo del pensamiento e ideología feminista el ir acomodando en los esquemas pasados, nuevas líneas de acción social. Nuestras preguntas van haciendo meya en las capacidades de recolocar las afirmaciones invariables de la ciencia que siguen conformando trajes a medida de quienes parecen mandar en este mundo. A lo mejor una Lisístrata nos vendría de perlas para este fin .

\section{REFERENCIAS BIBLIOGRÁFICAS}

Badinter, Elisabeth (1991). ¿Existe el instinto maternal?. Historia del amor maternal. Siglos XVII al XX en https://es.scribd. com/document/110721050/Badinter-Existe-el-instinto-maternal-Historia-del-amor-maternal-Siglos-XVII-al-XX.

Barreto, Lina; López, Paulina; Rosete, Laura; Santa, Fernanda. (2015) El mito del instinto materno: perspectiva psicosocial. Recuperado en http://vinculacion.dgire.unam.mx/Congreso-Trabajos-pagina/Trabajos-2015/5-Áreas\%20Convergentes/9.\%20CIN2015A50187.pdf.

Eyras, M. Carolina (2007) La teoría del Apego: instrumentos y articulaciones de un modelo integrador. Recuperado en http:// magix.ucu.edu.uy:8086/opac9/doctesis/psicologia/54287.pdf.

Gilbert, Jorge. (1997) Introducción a la sociología. Recuperado en https://books.google.es/books?id=fKHHZRqWK64C\&p$g=P A 164 \& l p g=P A 164 \& d q=i n s t i n t o+m a t e r n a l+$ sociologia\&source=bl\&ots=QmO3fMlKrK\&sig=g1TrHYPL4LLwBQusQTCRxFiBRjE\&hl=es\&sa=X\&ved=0ahUKEwiy4LTuhNXaAhVMPBQKHR-OAPEQ6AElcDAl\#v=onepage\&q\&f=false.

Manitta, Gabriela (2017) Del instinto maternal a la patolagización de las carencias maternas. PSIUC, Revista de Psicología nro. 3 Recuperado en http://www.ucongreso.edu.ar/wp-content/uploads/2017/09/2.-Del-instinto-maternal...-G.-Manitta.pdf.

Lagarde, Marcela (2006) Aculturación feminista. Texto publicado en «Género en el Estado. Estado en el género». Ediciones de las mujeres No 27, Isis Internacional. Artículo proporcionado por Modemmujer (México).

Luna, Jorge (2016) ¿Qué pasa si no sientes ningún deseo de ser madre? Blog: Código Nuevo. Recuperado en http://www. codigonuevo.com/mileniales/pasa-sientes-deseo-madre.

Rich, Adrienne. (2015) El «instinto materno», el invento más rentable del patriarcado. Blog eletrónico, en: http://www.lahojadearena.com/el-instinto-materno-el-invento-mas-rentable-del-patriarcado/.

Rodriguez, Andrea. (2017) El instinto materno, ¿existe o es una construcción social?. Periódico digital «El Telégrafo». Recuperado en https://www.eltelegrafo.com.ec/noticias/702/51/el-instinto-materno-existe-o-es-una-construccion-social

Trigilia, Adrián. (Sin fecha) El experimento de Harlow y la privación materna: sustituyendo a la madre. Blog digital Psicología y mente. Recuperado en https://psicologiaymente.net/psicologia/experimento-harlow-privacion-materna.

Villarreal, L. Ana. (2001) Revista Electrónica «Actualidades Investigativas en Educación», enero-junio, año/vol. 1, número 001. Universidad de Costa Rica. Recuperado en http://www.congresoed.org/wp-content/uploads/2014/10/Relaciones-de-poder-en-la-soc-patriarcal-.pdf.

Zicavo, Eugenia. (2013) Dilemas de la maternidad en la actualidad: antiguos y nuevos mandatos en mujeres profesionales de la ciudad de Buenos Aires. Revista de Estudios de Género. La ventana, vol. IV, núm. 38, 2013, pp. 50-87 Universidad de Guadalajara. Recuperado en http://www.redalyc.org/pdf/884/88430445004.pdf.

(N.A) (2013). ¿Existe o no el instinto materno?. Revista electrónica de la Universidad del Valle. Recuperado en http://uvsalud. univalle.edu.co/comunicandosalud/wp-content/uploads/2013/12/Existe-o-no-el-instinto-materno_DH5_04122013.pdf. 